\title{
ON THE STRUCTURE OF PRESSURE SYSTEMS
}

\author{
G. J. HALTINER \\ U.S. Naval Postgraduate School, Monterey, Calif. \\ and \\ LT. ROBERT F. ALDEN AND LT. GLENN C. ROSENBERGER
}

U.S. Navy

ABSTRACT

The three-dimensional distribution of vertical velocity and "isobaric" velocity divergence are numerically evaluated for a number of synoptic situations using Northern Hemisphere data at 1000, 850, 700, 500, and $300 \mathrm{mb}$. The results indicate that in the typical migratory nondeveloping cyclone only moderate values of divergence exist both in the low and high troposphere with minimum values near $500 \mathrm{mb}$. On the other hand, a developing cyclone, which deepened markedly at sea level but only slightly in the upper troposphere, displayed much larger values of divergence and vertical velocity, about double; and the level of minimum divergence lowered to 600-700 mb.

In addition, a new pair of positive and negative divergence centers appeared parallel to the east coast of the United States prior to the intensification which took place in the immediate neighborhood.

Similar calculations for a blocking situation gave small values of vertical velocity and divergence in a broad area in the vicinity of the bigh pressure ridge as contrasted to the normal migratory anticyclonic system.

Finally, computations of thermal advection with the divergent wind showed it to be as much as half of the nondivergent advection at $850 \mathrm{mb}$., but relatively smaller at upper levels.

\section{INTRODUCTION}

In the past decade a multitude of models have been developed for the purpose of numerical prediction of the pressure field. A by-product of the experimental and operational use of these models has been the temporal and spatial distribution of certain atmospheric parameters not directly obtainable by conventional observation. At the Naval Postgraduate School and the Fleet Numerical Weather Facility some experiments have been conducted with a five-level prediction model utilizing data at the $1000-, 850-, 700-$, 500-, and $300-\mathrm{mb}$. levels. The procedure involves the solution of the diagnostic vertical velocity equation

$\nabla^{2}(\sigma \omega)+\frac{p f \eta}{R} \frac{\partial^{2} \omega}{\partial p^{2}}=\nabla^{2}\left[\frac{g}{f} J(Z, T)\right]-J(T, \eta)-J\left(Z, \frac{g}{f} \nabla^{2} T\right)$

as developed by Haltiner, Clarke, and Lawniczak [3]. The vertical velocity is assumed to vanish at an upper boundary of $100 \mathrm{mb}$; while at the lower boundary, terrain and friction induce vertical motions which are applied at the height of a smoothed terrain.

The solution of this equation has been carried out twice daily for several years as a part of normal operations. An incidental result has been a greater insight into the structure of pressure systems. Several typical examples will be illustrated including a migratory cyclone during
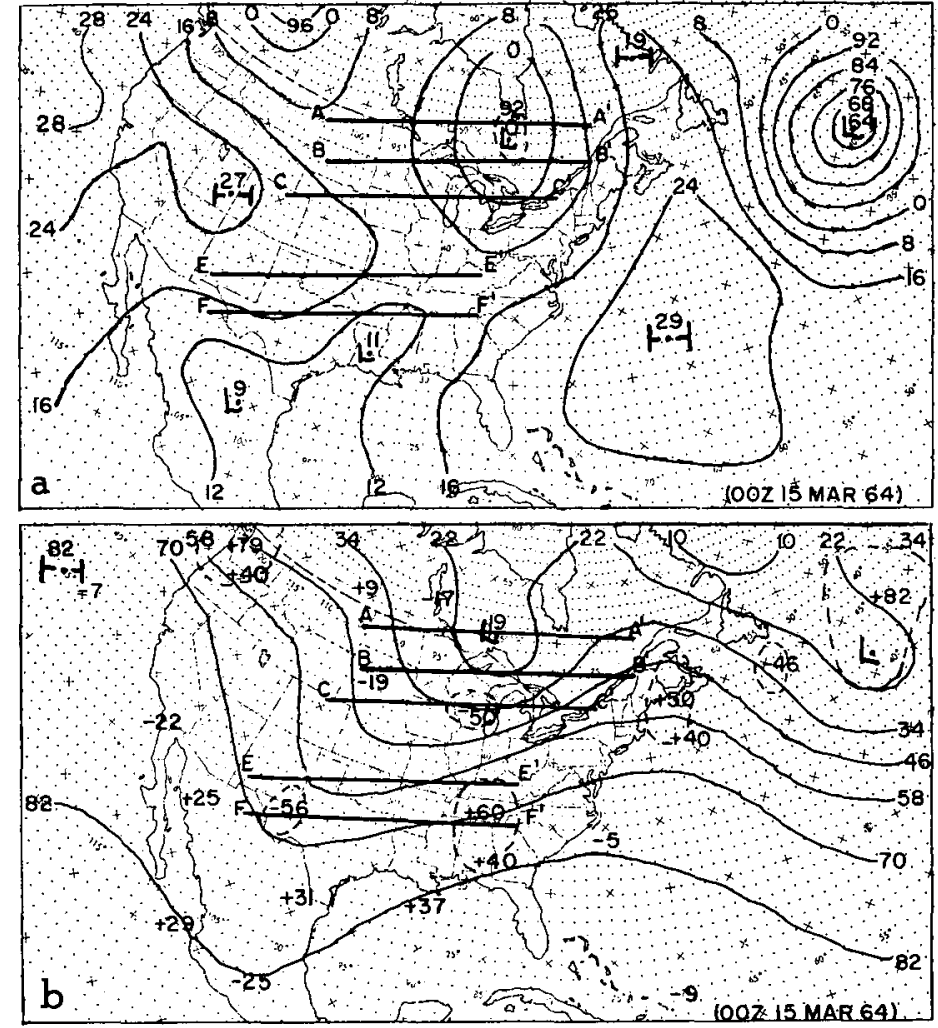

Figure 1.-(a) Surface pressure analysis $(16 \sim 1016 \mathrm{mb}$.). (b) $500-\mathrm{mb}$. divergence in units of $10^{-7} \mathrm{sec}^{-1}$ and $500-\mathrm{mb}$. analysis (34 5340 m.). 0000 Gмт March 15, 1964. 

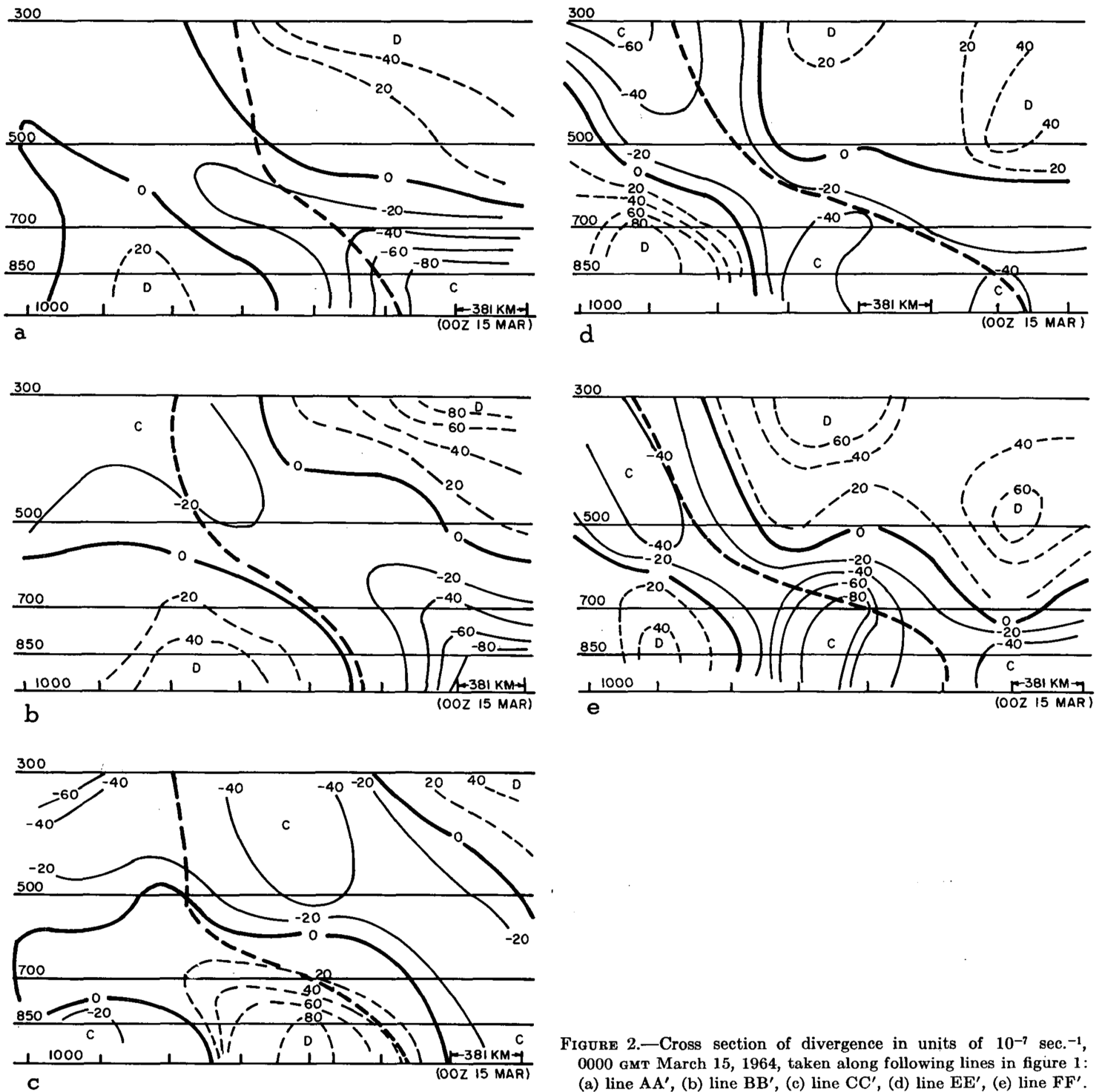

Figure 2.-Cross section of divergence in units of $10^{-7}$ sec. $^{-1}$, 0000 GMT March 15, 1964, taken along following lines in figure 1: (a) line $\mathrm{AA}^{\prime}$, (b) line $\mathrm{BB}^{\prime}$, (c) line $\mathrm{CC}^{\prime}$, (d) line $\mathrm{EE}^{\prime}$, (e) line $\mathrm{FF}^{\prime}$.

several stages of development and a blocking High. Emphasis here will be on the distributions of isobaric divergence as obtained from the vertical velocities via the continuity equation

$$
\nabla \cdot \mathbf{V}=-\frac{\partial \omega}{\partial p}
$$

The data input from five levels provides for considerable vertical resolution, permitting, for example, several levels of nondivergence. All computations were done on a Control Data Corporation 1604 computer over a square grid of 3969 points centered at the North Pole with a grid distance of $381 \mathrm{~km}$. at $60^{\circ} \mathrm{N}$. Although the grid covers the Northern Hemisphere, only small areas in the vicinity 

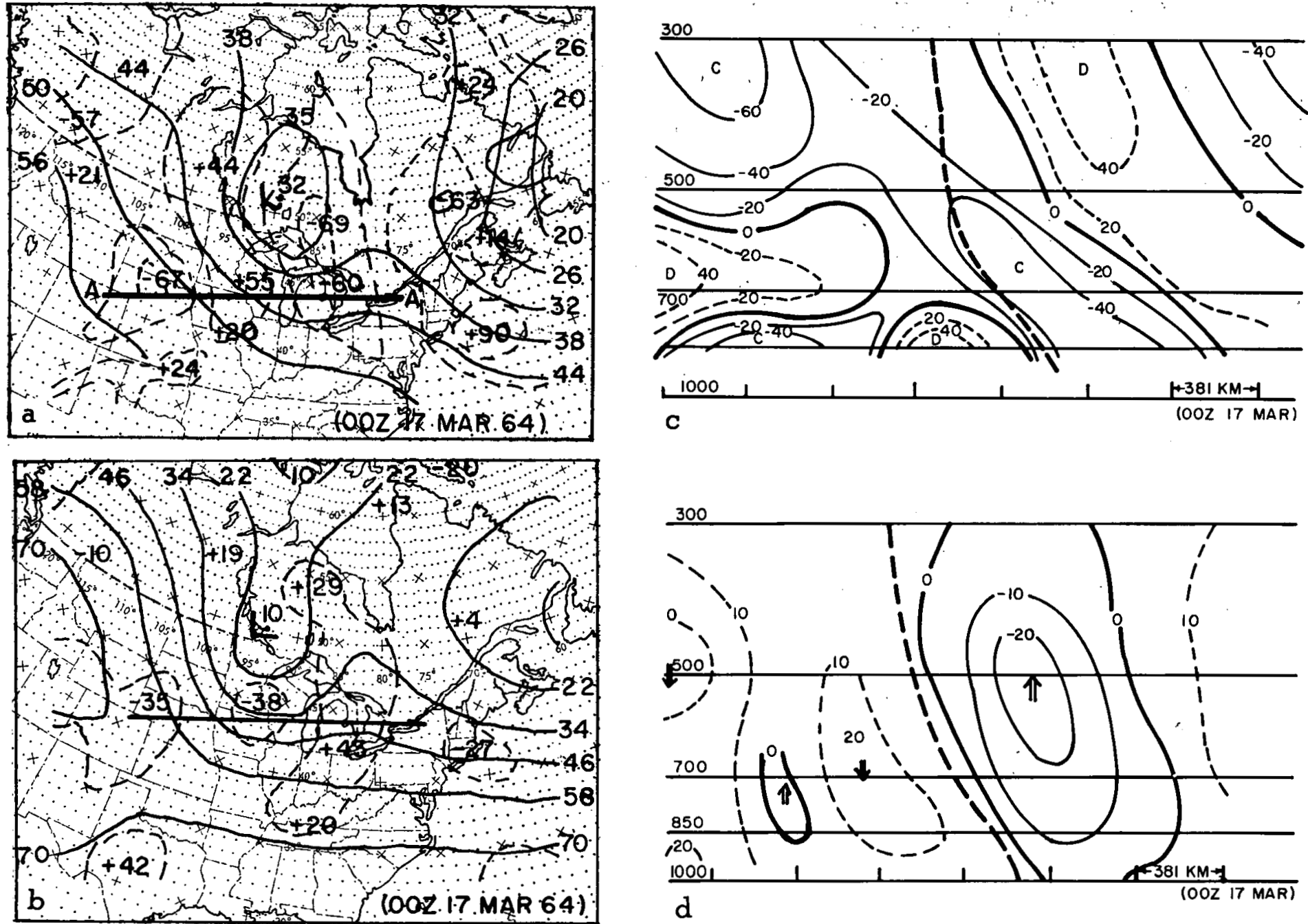

Figure 3.-0000 Gмт March 17, 1964. (a) 850-mb. divergence and height analysis $(50 \sim 1500 \mathrm{~m}$.). (b) 500-mb. divergence and height analysis $\left(22 \sim 5220 \mathrm{~m}\right.$.). (c) Cross section of divergence taken along line $\mathrm{AA}^{\prime}$ in $3 \mathrm{a}$. Divergence in units of $10^{-7}$ sec. ${ }^{-1}$. (d) Cross section of vertical velocity in units of $10^{-4} \mathrm{sec}^{-1}$ taken along line $\mathrm{AA}^{\prime}$ in $3 \mathrm{a}$.

of the pressure systems will be exhibited. The few examples shown are considered representative of many other similar cases examined in detail. Moreover, only a small selection of the many charts constructed are actually portrayed; however, it is felt that the pertinent features are included.

\section{EXAMPLES}

\section{CYCLONE, MARCH 15, 1964}

The first case illustrates the variety of patterns of isobaric velocity divergence appearing in different cross sections through a particular trough. Figures $1 \mathrm{a}$ and $1 \mathrm{~b}$ are the surface and 500-mb. analyses for 0000 GMT March 15, 1964, while figure 2 (a-e) shows vertical cross sections depicting velocity divergence (units $10^{-7} \mathrm{sec}^{-1}$ ) along the lines $\mathrm{AA}^{\prime}, \mathrm{BB}^{\prime}, \mathrm{CC}^{\prime}, \mathrm{EE}^{\prime}$, and $\mathrm{FF}^{\prime}$ of figure 1 . The position of the trough line along the vertical is deline$769-4210-65-4$ ated by a heavy dashed line. The patterns are generally similar to the classical concept (see for example, Fleagle [2]) with low-level convergence to the east and near the trough surmounted by high-level divergence, and vice versa to the west. However, there are significant deviations including several levels of nondivergence in some locations and considerable variability along the trough line.

This particular system displayed no significant intensification at any level during the preceding $12 \mathrm{hr}$. except for a slight increase.in circulation at $500 \mathrm{mb}$., nor did it show any intensification during the next $12 \mathrm{hr}$. as it moved steadily eastward.' This was followed by slight deepening (about $6 \mathrm{mb}$.) at the surface but not aloft during the following $12 \mathrm{hr}$. The cross sections appear to suggest that on the average there is a layer of convergence in the vicinity of the trough, though not of large magnitude (see Cressman [1]). 

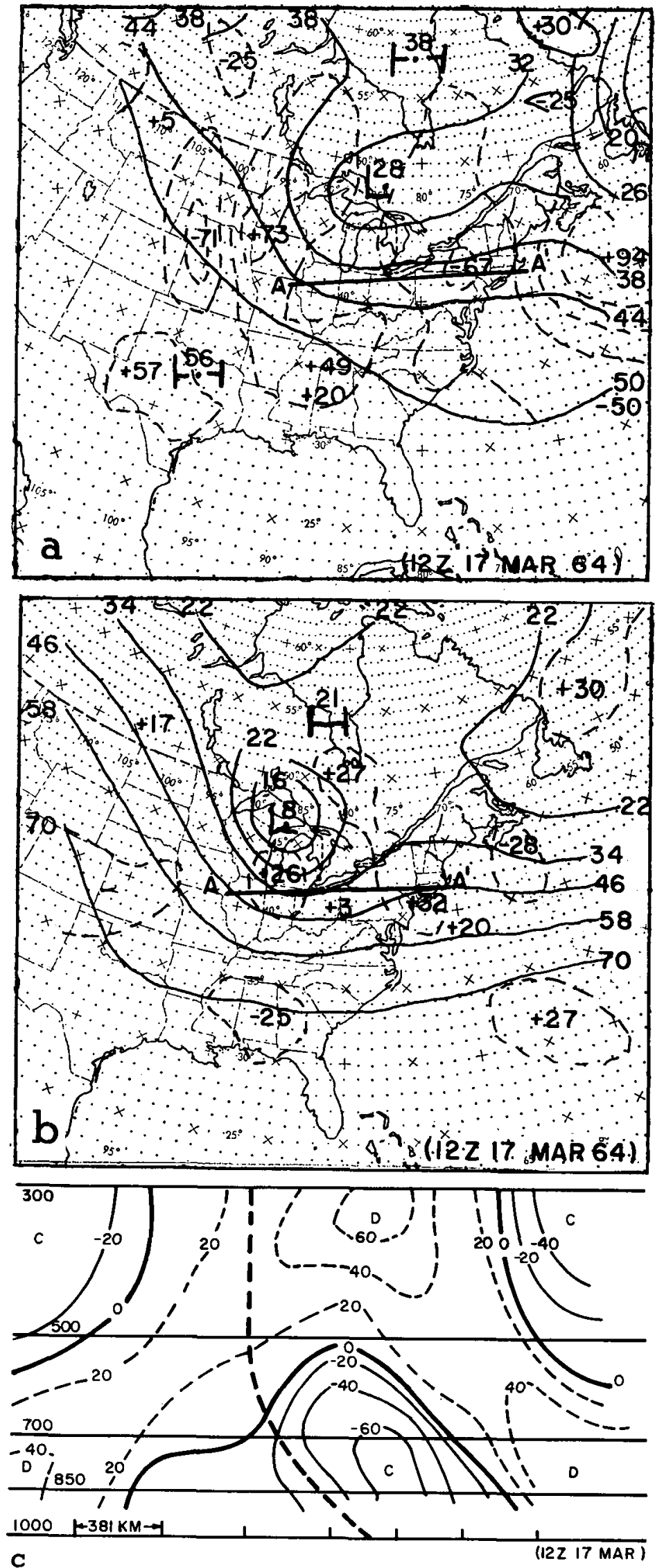

FIGURE 4.-1200 GMT March 17, 1964. (a) 850-mb. divergence and height analysis $(50 \sim 1500 \mathrm{~m}$.). (b) $500-\mathrm{mb}$. divergence and height analysis $(22 \sim 5220 \mathrm{~m}$.). (c) Cross section of divergence taken along line $\mathrm{AA}^{\prime}$ in $4 \mathrm{a}$. Divergence in units of $10^{-7} \mathrm{sec}^{-1}$.

\section{CYCLONE, MARCH 17-19, 1964}

Figures $3 \mathrm{a}$ and $3 \mathrm{~b}$ are the $850-$ and $500-\mathrm{mb}$. analyses for 0000 GMT March 17, 1964. The dashed lines represent the isobaric divergence in units of $10^{-7}$ sec. $^{-1}$. Figures 3c and $3 \mathrm{~d}$ depict the isobaric divergence and vertical velocity for a vertical cross section along the line $\mathbf{A A}^{\prime}$ of figure $3 \mathrm{a}$. The magnitudes of these parameters are moderate to small and there was little change of intensity of the cyclonetrough system occurring.

In figure 4 are the 850 - and $500-\mathrm{mb}$. analyses and vertical cross section for $1200 \mathrm{GMT}$ March 17, 1964. The surface Low has filled slightly while the $500-\mathrm{mb}$. circulation increased considerably though with only slight deepening.

Figures 5a, b, and c are similar charts for 0000 GMT March 18. The system has shown little change in intensity with a steady eastward progression during the past $12 \mathrm{hr}$. On the other hand, the cross sections of divergence and vertical velocity along the line $\mathrm{BB}^{\prime}$ (of fig. 5a), as depicted in figures $5 \mathrm{~d}$ and $\mathrm{e}$, show a line of intensified centers of divergence paralleling the east coast. The level of nondivergence appears near $700 \mathrm{mb}$. These centers of divergence intensify further on the $1200 \mathrm{GMT}$ March 18 maps shown in figure 6, as well as on the 1000- and 300-mb. maps which are not shown. By this time the sea level cyclone had begun to deepen, about $5 \mathrm{mb}$. during the past $12 \mathrm{hr}$.

The 0000 GMT March 19 charts are shown in figure 7. The intensification of the sea level cyclone continued during this period and by 1200 GMT March 19, the central pressure was about $972 \mathrm{mb}$., reflecting a deepening of over $25 \mathrm{mb}$. during the past $24 \mathrm{hr}$. Though the cross sections show strongly developed divergence, the centers of maximum intensity which are southeast of the cross section line, are even larger, as may be observed on the 850- and 500-mb. charts.

The 1200 GMT March 19 charts in figure 8 again show strongly developed centers of divergence and vertical velocity. During the preceding $12 \mathrm{hr}$. the $500-\mathrm{mb}$. center deepened about $60 \mathrm{~m}$., a comparatively modest development compared to the marked deepening of the sea level system. The data suggest that the sea level deepening is accompanied by an overall increase in the magnitude of the centers of convergence, divergence, and vertical velocity as well as a lowering of the mean level of nondivergence ordinarily found in the vicinity of $500 \mathrm{mb}$. The former concept appears to be implied in Sutcliffe's [4] development equation.

\section{BLOCKING SITUATION, FEBRUARY 13, 1964}

Figures $9 a, b$, and $c$ show the distribution of isobaric divergence at the 850- 500- and 300-mb. levels for a "blocking" situation. Note the relatively small magnitudes, particularly aloft, in the vicinity of the ridge. Figures $9 \mathrm{~d}$ and e display velocity divergence and vertical velocity $\omega$ in cross section form along the line shown in figure 9a. Note again the relatively small vertical ve- 

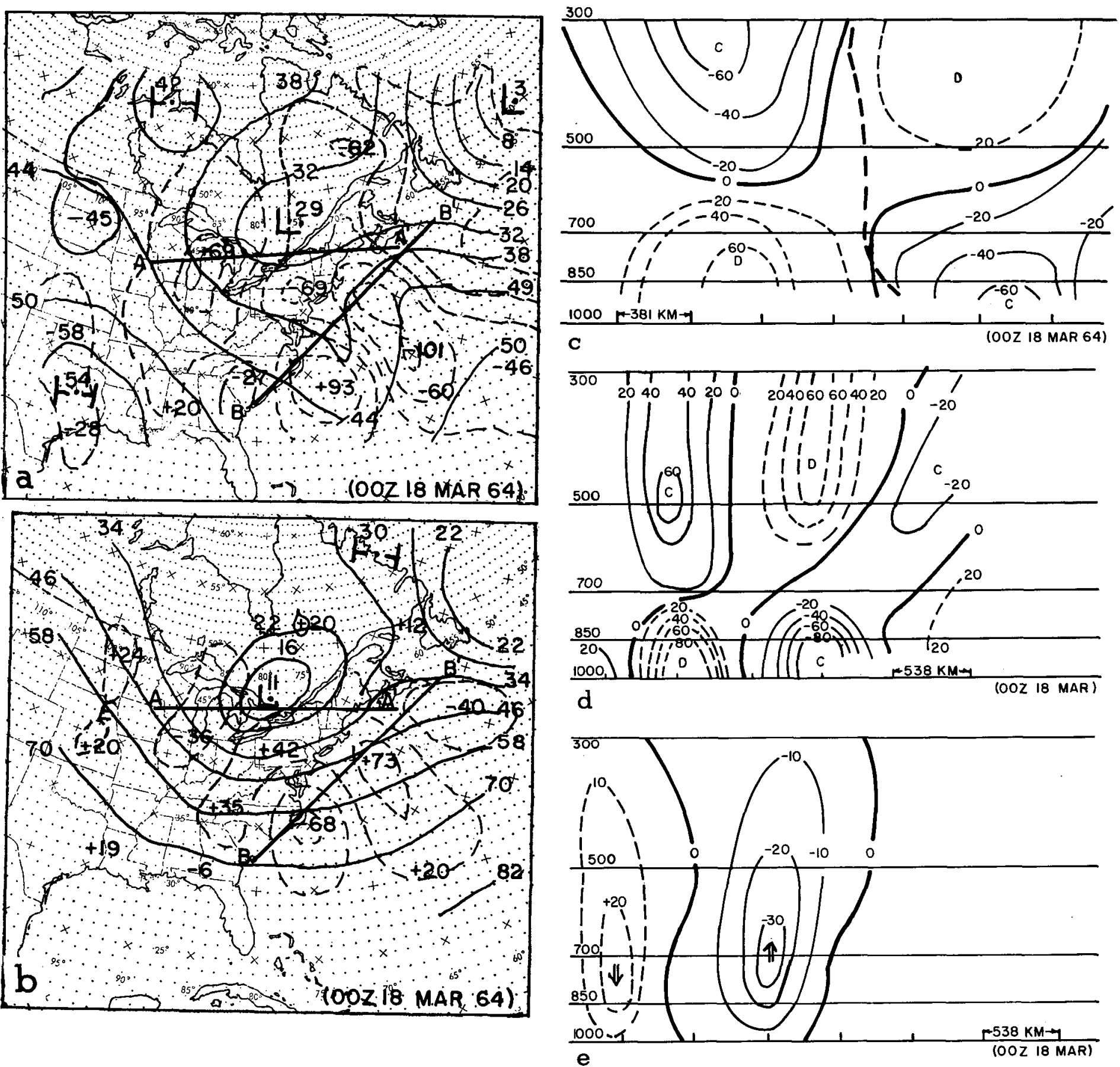

Figdre 5.-0000 GMT March 18, 1964 . (a) $850-\mathrm{mb}$. divergence and height analysis $(50 \sim 1500 \mathrm{~m}$.). (b) 500 -mb. divergence and height analysis $\left(22 \sim 5220 \mathrm{~m}\right.$.). (c) Cross section of divergence taken along line $\mathrm{AA}^{\prime}$ in $5 \mathrm{a}$. (d) Cross section of divergence taken along line $\mathrm{BB}^{\prime}$ in 5a. Divergence in units of $10^{-7} \mathrm{sec} .^{-1}$. (e) Cross section of vertical velocity in units of $10^{-4}$ sec..$^{-1}$ taken along line $\mathrm{BB}^{\prime}$ in $5 \mathrm{a}$.

locities and corresponding isobaric divergence in a fairly broad band extending on either side of the ridge (denoted by a dotted line). The various diagrams clearly indicate the stagnant nature of the blocking situation.

\section{THERMAL ADVECTION}

Integral relations have demonstrated the need for including the thermal advection with the divergent part of 

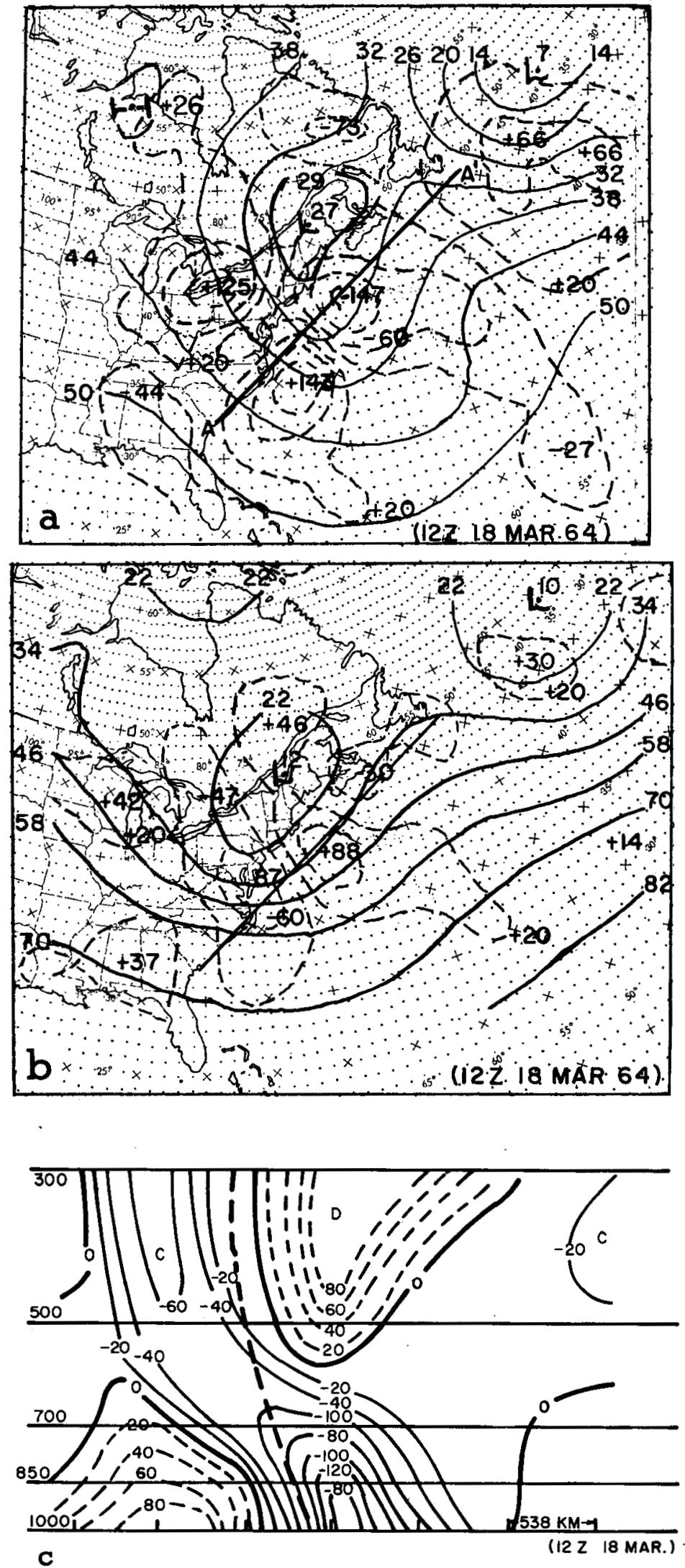

Figure 6.-1200 GMT March 18, 1964. (a) $850-\mathrm{mb}$. divergence and height analysis $(50 \sim 1500 \mathrm{~m}$.). (b) $500-\mathrm{mb}$. divergence and height analysis $(22 \sim 5220 \mathrm{~m}$.). (c) Cross section of divergence taken along line $\mathrm{AA}^{\prime}$ in $6 a$. Divergence in units of $10^{-7} \mathrm{sec}^{-1}$.
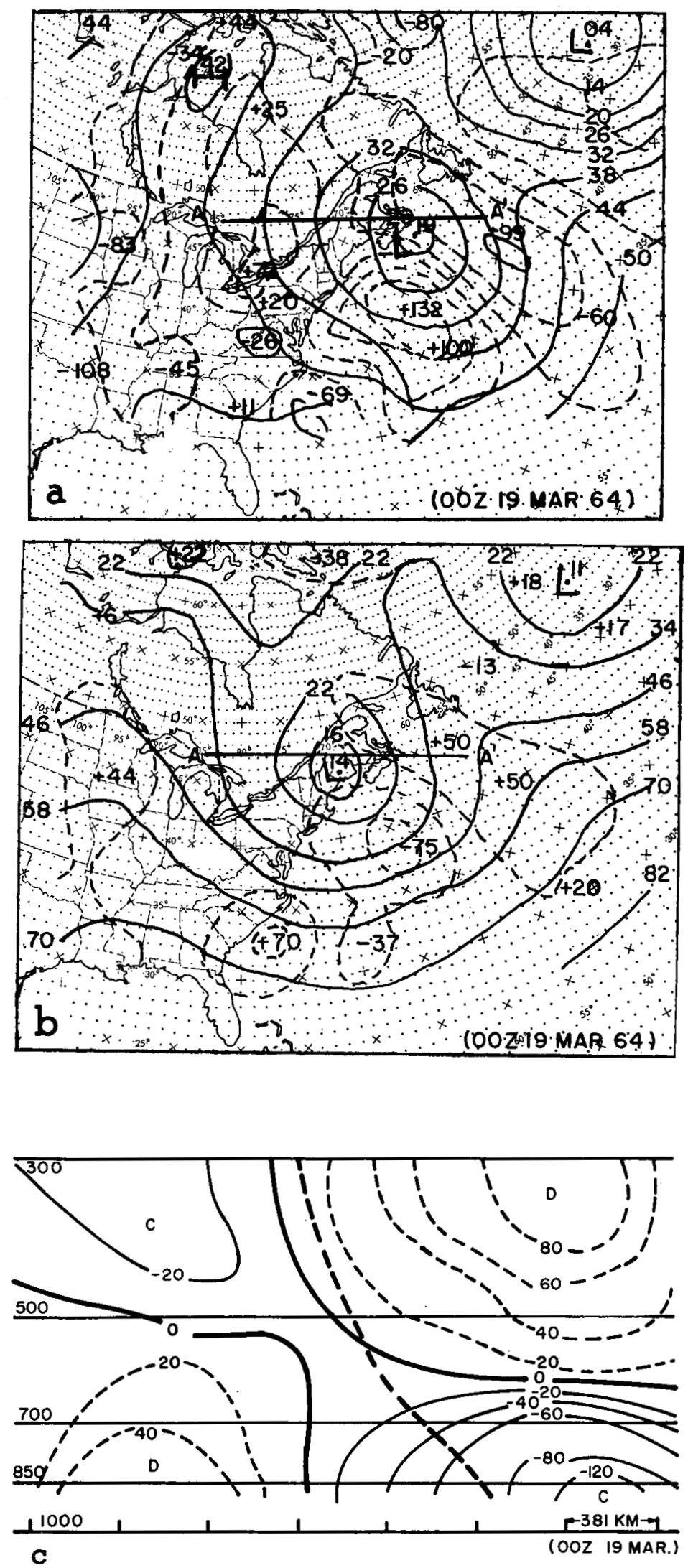

FiguRe 7.-0000 GMT March 19, 1964. (a) 850-mb. divergence and height analysis $(50 \sim 1500 \mathrm{~m}$.). (b) $500-\mathrm{mb}$. divergence and height analysis $(22 \sim 5220 \mathrm{~m}$.). (c) Cross section of divergence taken along line $\mathrm{AA}^{\prime}$ in $7 \mathrm{a}$. Divergence in units of $10^{-7}$ sec. $^{-1}$. 

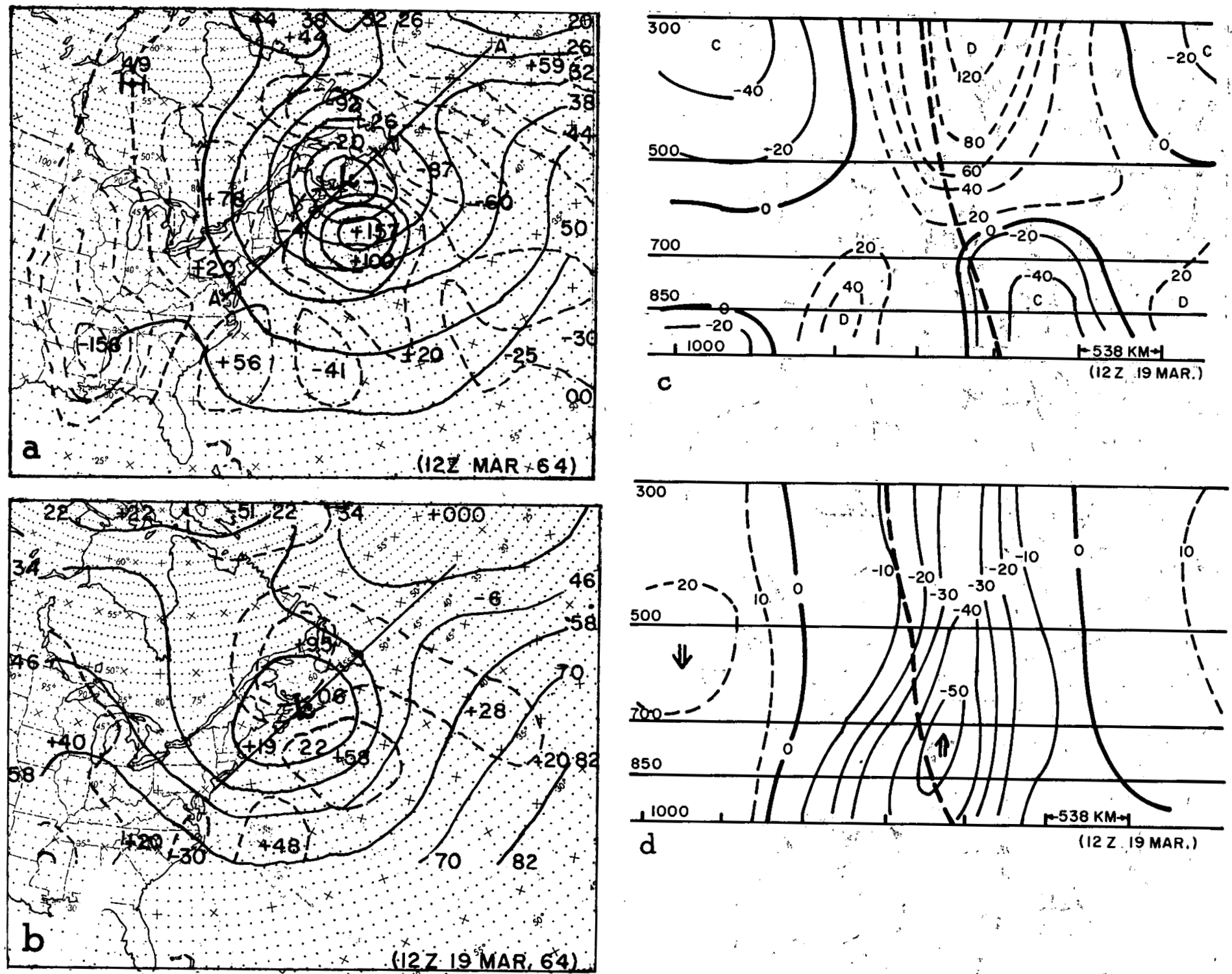

FrGURE: 8.-1200 GMT March 19, 1964.. (a) $850-\mathrm{mb}$. divergence and height analysis $(50 \sim 1500 \mathrm{~m}$.). (b) $500-\mathrm{mb}$. divergence and height analysis $\left(22 \sim 5220 \mathrm{~m}\right.$.). (c) Cross section of divergence taken along line $\mathrm{AA}^{\prime}$ in 8a. Divergence in units of $10^{-7}$ sec. ${ }^{-1}$. (d) Cross section of 'vertical velocity in units of $10^{-4}$ sec.-1 taken along line $\mathrm{AA}^{\prime}$ in $8 \mathrm{a}$.

the wind if a variable static stability parameter is permitted. Having computed the velocity divergence, only a simple Poisson relaxation is necessary to obtain the velocity potential $\chi$ for the divergent wind component $\mathbf{v}_{x}$, namely

$$
\begin{aligned}
& \nabla^{2} \chi=\nabla \cdot \mathbf{V}=-\frac{\partial \omega}{\partial p} \\
& \mathbf{V}_{\boldsymbol{x}}=\nabla x
\end{aligned}
$$

This wind was used to compute the thermal advection $-V_{\chi} \cdot \nabla T$, for purposes of comparison with advection with the nondivergent wind, $-\mathbf{V}_{\psi} \cdot \nabla T$, where $\mathbf{V}_{\psi}=\mathbf{k} \times \nabla \psi$, the stream function $\psi$ being obtained by solution of the balance equation.

An example of this computation is shown in figure 10 . Comparison of the centers of maximum magnitude indicates that at $850 \mathrm{mb}$. the advection with the divergent wind may be easily half the nondivergent advection in some areas and certainly should not be omitted. Thermal advection with the divergent wind was somewhat smaller at $500 \mathrm{mb}$. in this case.

Obviously, thermal advection with only the nondivergent (or rotational) wind may have significant errors with respect to temperature changes. It is interesting to note nevertheless that a comparison of the prediction 

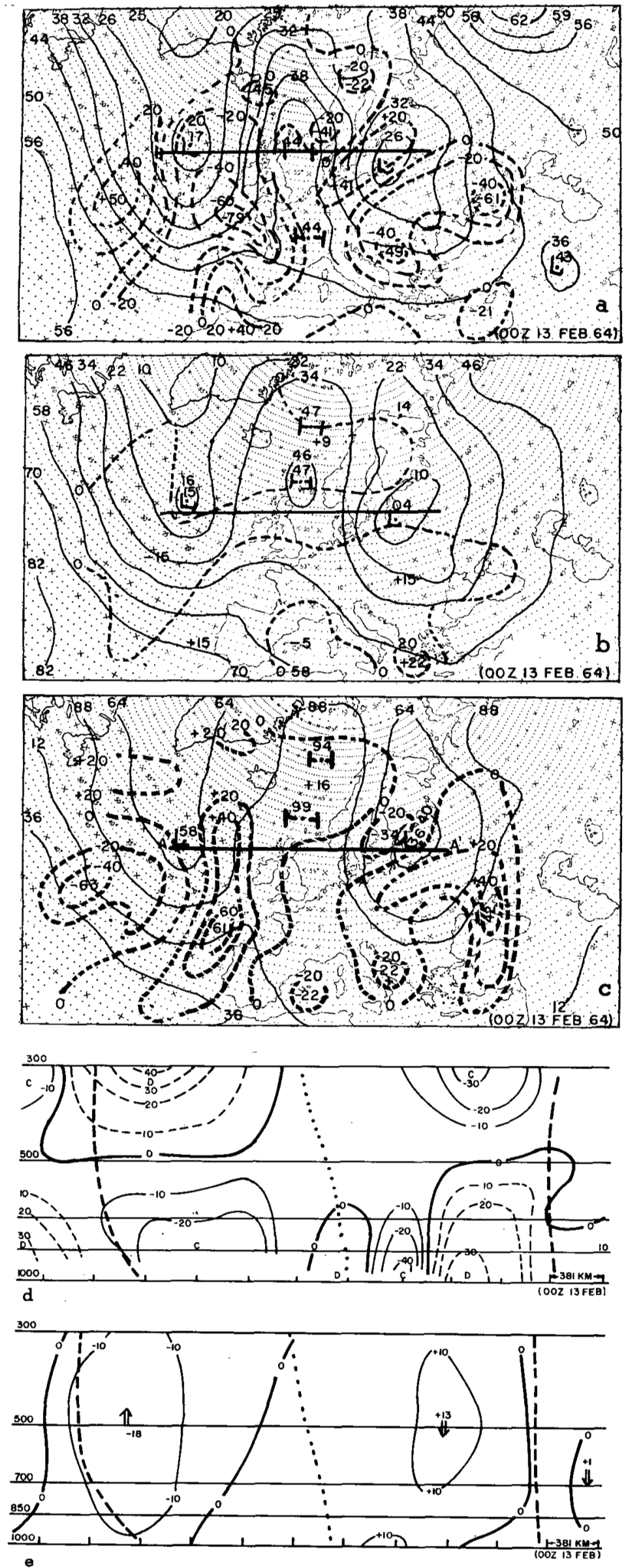
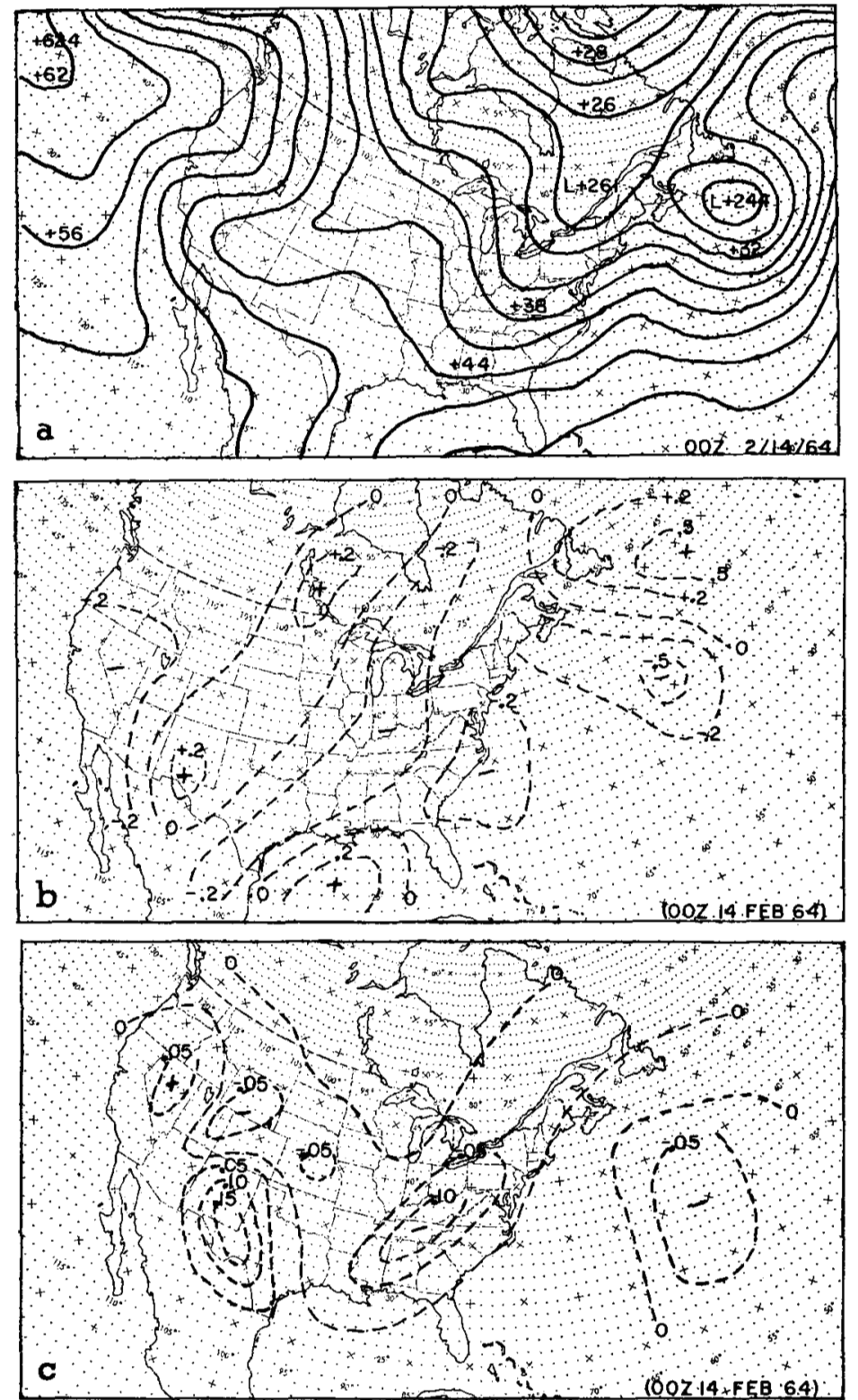

Figtre 10.-0000 GMT February 14, 1964. (a) 850-mb. height analysis $(50 \sim 1500 \mathrm{~m}$.). (b) $850-\mathrm{mb}$. thermal advection with the nondivergent wind in ${ }^{\circ} \mathrm{C}$. $\mathrm{hr}^{-1}$. (c) $850-\mathrm{mb}$. thermal advection with the divergent wind in ${ }^{\circ} \mathrm{C} . \mathrm{hr}^{-1}$.
Figdre 9.-0000 GMT February 13,1964 . (a) 850 -mb. divergence and height analysis $(50 \sim 1500 \mathrm{~m}$.). (b) $500-\mathrm{mb}$. divergence and height analysis $(22 \sim 5220 \mathrm{~m}$.). (c) $300-\mathrm{mb}$. divergence and height analysis $(12 \sim 9120 \mathrm{~m}$.). (d) Cross section of divergence taken along line $\mathrm{AA}^{\prime}$ in $9 \mathrm{c}$. Divergence in units of $10^{-7}$ sec.-1. (e) Cross section of vertical velocity in units of $10^{-4}$ sec. $^{-1}$ taken along line $\mathrm{AA}^{\prime}$ in $9 \mathrm{c}$. 
errors of three different five-level baroclinic models, one of which included the divergent (or irrotational) wind component, showed no significant differences. However, since the sample size was very small, the test may not be considered conclusive.

\section{REFERENCES}

1. G. P. Cressman, "A Diagnostic Study of Mid-Tropospheric Development," Monthly Weather Review, vol. 89, No. 3, Mar. 1961, pp. 74-82.
2. R. F. Fleagle, "Quantitative Analysis of Factors Influencing Pressure Change," Journal of Meteorology, vol. 5, No. 6, Dec. 1948, pp. 281-292.

3. G. J. Haltiner, L. C. Clarke, and G. E. Lawniczak, Jr., "Computation of the Large Scale Vertical Velocity," Journal of Applied Meteorology, vol. 2, No. 2, Apr. 1963, pp. 242-259.

4. R. C. Sutcliffe, "A Contribution to the Problem of Development," Quarterly Journal of the Royal Meteorological Society, vol. 73, Nos. 317-318, July/Oct. 1947, pp. 370-383.

[Received October 21, 1964; revised December 21, 1964] 